\title{
The Most Accurate and Fastest Method for Confirmation of Endotracheal Intubation
}

\author{
Zahra Parsian¹, Farzad Rahmani ${ }^{2}$, Hassan Soleimanpour ${ }^{3 *}$ \\ 1- Students' Research Committee, Tabriz University of Medical Sciences, Tabriz, IR Iran \\ 2- Emergency Medicine Research Team, Tabriz University of Medical Sciences, Tabriz, IR Iran \\ 3- Cardiovascular Research Center, Tabriz University of Medical Sciences, Daneshgah Street, Tabriz, 51664, \\ Iran
}

Tracheal intubation and confirming correct placement of tracheal tube is one of the most important subjects in patients who need airway management (1). Gold standard method of confirmation is capnography, but it is just applicable in patients with tangible cardiac output. Other methods of confirming endotracheal intubation such as hearing gurgling sounds in epigastria, auscultation of lungs sounds, esophageal detector device, and chest radiography can be used for this purpose .(2) Recently an exact real time, contrary to other methods, method of confirming endotracheal intubation has been developed which is direct visualization of tracheal tube passage through trachea with sonography. Considering the advantages of sonography, it is strongly recommended for the confirmation of endotracheal intubation.(3)

\section{Acknowledgments}

This article was written based on dataset of Zahra Parsian's Special thesis entitled, Diagnostic Value of Sonography for Confirmation of Endotracheal Intubation in Emergency Department. This study was registered in Tabriz University of Medical Sciences (No: 93/3-7/30).

\section{References}

1. Soleimanpour H, Gholipouri C, Panahi JR, Afhami MR, Ghafouri RR, Golzari SE, et al. Role of anesthesiology curriculum in improving bagmask ventilation and intubation success rates of emergency medicine residents: a prospective descriptive study. BMC Emerg Med 2011;11:8.

2. Soleimanpour H, Rahman F. Role of Sonography for Post Intubation Confirmation. Emergency Med; 2014 4:e135.

3. Hassan Soleimanpour, Farzad Rahman, Zahra Parsian. et al. (2014) Diagnostic Value of Sonography for Confirmation of Endotracheal Intubation in Emergency Department. Cardiovascular Research Center, Tabriz University of Medical Sciences, Daneshgah Street, Tabriz, 51664, Iran

\section{Corresponding author:}

Hassan Soleimanpour

Cardiovascular Research Center, Tabriz University of Medical Sciences, Daneshgah Street, Tabriz, 51664, Iran

E-mail: soleimanpourh@tbzmed.ac.ir

Receive date: 2017-06-20 | Accept date: 2017-09-01 | Publish date: 2017-10-01

DOI: 10.7575/aiac.abcmed.17.05.04.05 